\title{
Front Matter: Volume 11340
}

, "Front Matter: Volume 11340," Proc. SPIE 11340, AOPC 2019: Optical Fiber Sensors and Communication, 1134001 (18 December 2019); doi: 10.1117/12.2564047

SPIE. Event: Applied Optics and Photonics China (AOPC2019), 2019, Beijing, China 


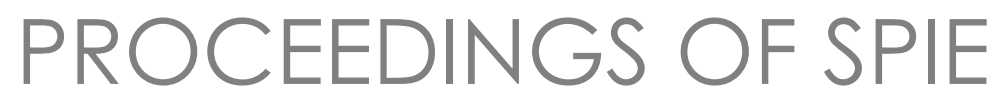

\title{
AOPC 2019: Optical Fiber Sensors and Communication
}

\author{
Jie Zhang \\ Songnian Fu \\ Jun Yang \\ Editors
}

\section{5-8 August 2019}

Beijing, China

\section{Sponsored by}

Chinese Society for Optical Engineering (China)

Cosponsored by

SPIE

Organized by

Chinese Society for Optical Engineering (China)

Photoelectronic Technology Committee, Chinese Society of Astronautics (China)

Science and Technology on Low-light-level Night Vision Laboratory (China)

Science and Technology on Electro-Optical Information Security Control Laboratory (China)

Academy of Opto-Electronics of Electronics Technology of China (China)

Infrared and Laser Engineering (China)

Published by

SPIE

Volume 11340 
The papers in this volume were part of the technical conference cited on the cover and title page. Papers were selected and subject to review by the editors and conference program committee. Some conference presentations may not be available for publication. Additional papers and presentation recordings may be available online in the SPIE Digital Library at SPIEDigitalLibrary.org.

The papers reflect the work and thoughts of the authors and are published herein as submitted. The publisher is not responsible for the validity of the information or for any outcomes resulting from reliance thereon.

Please use the following format to cite material from these proceedings:

Author(s), "Title of Paper," in AOPC 2019: Optical Fiber Sensors and Communication, edited by Jie Zhang, Songnian Fu, Jun Yang, Proceedings of SPIE Vol. 11340 (SPIE, Bellingham, WA, 2019) Seven-digit Article CID Number.

ISSN: 0277-786X

ISSN: 1996-756X (electronic)

ISBN: 9781510634527

ISBN: 9781510634534 (electronic)

Published by

SPIE

P.O. Box 10, Bellingham, Washington 98227-0010 USA

Telephone +13606763290 (Pacific Time) · Fax +1 3606471445

SPIE.org

Copyright @ 2019, Society of Photo-Optical Instrumentation Engineers.

Copying of material in this book for internal or personal use, or for the internal or personal use of specific clients, beyond the fair use provisions granted by the U.S. Copyright Law is authorized by SPIE subject to payment of copying fees. The Transactional Reporting Service base fee for this volume is $\$ 21.00$ per article (or portion thereof), which should be paid directly to the Copyright Clearance Center (CCC), 222 Rosewood Drive, Danvers, MA 01923. Payment may also be made electronically through CCC Online at copyright.com. Other copying for republication, resale, advertising or promotion, or any form of systematic or multiple reproduction of any material in this book is prohibited except with permission in writing from the publisher. The CCC fee code is 0277$786 \times / 19 / \$ 21.00$.

Printed in the United States of America by Curran Associates, Inc., under license from SPIE.

Publication of record for individual papers is online in the SPIE Digital Library.

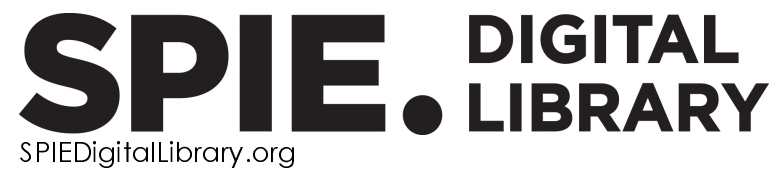

Paper Numbering: Proceedings of SPIE follow an e-First publication model. A unique citation identifier (CID) number is assigned to each article at the time of publication. Utilization of CIDs allows articles to be fully citable as soon as they are published online, and connects the same identifier to all online and print versions of the publication. SPIE uses a seven-digit CID article numbering system structured as follows:

- The first five digits correspond to the SPIE volume number.

- The last two digits indicate publication order within the volume using a Base 36 numbering system employing both numerals and letters. These two-number sets start with $00,01,02,03,04$, 05, 06, 07, 08, 09, OA, OB ... 0Z, followed by 10-1Z, 20-2Z, etc. The CID Number appears on each page of the manuscript. 


\title{
Contents
}

\author{
vii $\quad$ Authors \\ vi Conference Committee \\ xiii Introduction
}

OPTICAL FIBER SENSORS AND COMMUNICATION

1134002 Application research on health monitoring of Sutong Bridge based on distributed optical fiber sensing [1 1340-1]

1134003 Research on particle swarm optimization algorithm for space optical-fiber coupling auto-alignment platform [1 1340-2]

1134004 Design and experimental investigation of novel irradiation resistant and high bandwidth multimode fiber [1 1340-3]

1134005 A testing system of analyzing reliability induced by the FOG coil [1 1340-4]

1134006 Discussion and experimental verification of defocus amount and field of view in laser communication [11340-6]

$1134007 \quad$ A high-resolution optical-fiber imaging sensor [1 1340-7]

1134008 Design of a sensitivity-enhanced optical fiber magnetic field sensor based on magnetostrictive composite [11340-8]

$1134009 \quad$ Analysis of polarization characteristic in a FOG fiber coil using OCDP [1 1340-9]

11340 OA Design of a sensitivity-enhanced FBG strain sensor and its application in state estimation for lithium-ion battery [1 1340-10]

$11340 \mathrm{OB} \quad$ Fault diagnosis algorithm of fiber current transformer based on Wavelet-Allan variance [11340-11]

11340 OC The microstructure evolution of PCFs in heating process: a novel model and experimental validation [11340-13]

11340 OD FOG fiber coil reliability assessment based on Bayesian estimation method [1 1340-14]

11340 OE Pressure and bending sensing of soft fingers based on FBG [1 1340-15]

11340 OF Research on code group routing allocation strategy based on soft defined multi-granular switching system [1 1340-16] 
$113400 G$

$11340 \mathrm{OH}$

113400

$11340 \mathrm{JJ}$

11340 OK

$11340 \mathrm{OL}$

$113400 \mathrm{OM}$

11340 ON

1134000

$11340 \mathrm{OP}$

$113400 Q$

$11340 \mathrm{OR}$

11340 OS

11340 OT

11340 OU

11340 OV

11340 OW

$113400 x$

11340 OY

1134002

Research on PCEP protocol for softened multi-granularity switching networks [1 1340-17]

Reliability evaluation of high precision fiber optic gyroscope based on temperature and humidity dual stress Peck model [11340-18]

Acoustic field modeling and experimental research of an overflow cavity fiber optic hydrophone based on COMSOL simulation [1 1340-19]

The study of large-broadband OAM mode converter based on helical long period fiber grating [11340-21]

Research on inter-domain routing and optical code assignment based on hierarchical stateful PCE [1 1340-22]

Intrusion signal extraction and recognition for optical fiber perimeter system using improve CFAR and support vector machine [11340-25]

RPT performance evaluating based on the evenly distributed measurement points [1 1340-26]

Optical-path difference on-line measurement of multiplexing fiber-optic interferometric sensors using TDM and WDM by improved optical-frequency-domain reflectometry [1 1340-27]

Method for fusion splicing polarization-maintaining photonic crystal fibers and conventional polarization-maintaining fiber [1 1340-28]

Research on impact energy measurement based on FBG and damping attenuation [1 1340-29]

Qiongzhou Strait shipping network ship supervision system based on NB-loT [1 1340-31]

High-selectivity microstrip bandpass filter using triple-mode resonators [1 1340-32]

A self-temperature compensation method of fiber optic gage use for strain balances [11340-34]

Ultra low loss hollow-core anti-resonant fiber for multiplexing communication with cylindrical vector beams [11340-35]

Structure of terahertz fibers and their applications [1 1340-37]

A novel demodulation algorithm for CMOS camera-based VLC using adjacent pixel threshold [11340-39]

Fiber Bragg grating temperature sensor coated with graphene thin film [1 1340-43]

Design on FBG wavelength demodulation system with edge filter [1 1340-44]

Research on high-speed dynamic calibration technology of tunable laser [1 1340-45]

Research on a large-range three-coil coaxial optical fiber displacement sensor [1 1340-46]

iv 
1134010 Research on fiber Bragg grating sensor for pressure and temperature double-parameter detection [1 1340-47]

$1134011 \quad$ Research on key technologies of high precision fiber Bragg grating demodulation system [1 1340-48]

1134012 Theoretical and experimental analysis of fiber ring resonator for resonant fiber optic gyroscope based on total internal reflection photonic crystal fiber [1 1340-50]

$1134013 \quad$ Fiber microphone based on distributed acoustic sensing [1 1340-52]

1134014 Theoretical study of optimal gauge length in a helically wound cable for distributed acoustic sensing system [1 1340-54]

1134015 Research on environmental adaptability evaluation of optical communication equipment [1 1340-55]

1134016 Sea trial of 16-element DFB-FL hydrophone towed array [1 1340-56]

$1134017 \quad$ Hierarchical MEC deployment and workload assignment in C-RAN over WDM ring networks [11340-57]

$1134018 \quad$ Experiment and research of twins fiber on pump coupling efficiency and thermal management [1 1340-59]

1134019 A variable-length transmission division scheme for TDM-PON based fronthaul [11340-60]

$113401 \mathrm{~A} \quad$ Analysis and experiment of random walk coefficient of high precision fiber optic gyroscope [11340-61]

11340 1B Study on synthesis of UV potting adhesive and the temperature characteristics of optical fiber coil [1 1340-62]

11340 1C Research on noise suppression technology of high precision fiber optic gyroscope [1 1340-63]

11340 1D FBG strain signal collection and its fault feature analysis for ring gear crack of planetary transmission in wind turbine [1 1340-64]

$113401 \mathrm{E} \quad$ IPRAN networking cost optimization program research [1 1340-65]

$113401 \mathrm{~F} \quad$ Network operation state evaluation method based on random forest classification under IP+optical [1 1340-66]

$113401 \mathrm{G} \quad$ A path and algorithm scoring method for automatic planning and optimization of optical networks [1 1340-67]

$113401 \mathrm{H} \quad$ Analysis of access network requirements based on similar service feature values clustering [1 1340-68] 
$1134011 \quad$ The high temperature sensor based on a $45^{\circ}$ fiber cantilever beam fabricated by femtosecond laser [1 1340-69]

$113401 \mathrm{~J} \quad$ Analysis of temperature-insensitive sensor probe for SRI measurement via etched cladding FM-FBG [1 1340-70]

$113401 \mathrm{~K} \quad$ Fiber Bragg grating process embedded in carbon fiber reinforced composites [1 1340-71]

$113401 \mathrm{~L} \quad$ Dual biconical fiber-optic sensor for vital signs monitoring [1 1340-72]

$113401 \mathrm{M} \quad$ Coal mine low power laser methane detection and alarm instrument [1 1340-73]

$113401 \mathrm{~N} \quad$ Design of ASE source for high precision FOG [11340-74]

$1134010 \quad$ Modeling the performance of distributed fiber optical sensor based on spontaneous Brillouin scattering [1 1340-76]

11340 1P Research and application of intelligent fiber detection system for perimeter security [1 1340-77]

$113401 Q \quad$ Application and research of wireless laser methane sensor in drainage pipeline monitoring [1 1340-78]

$113401 R \quad$ Application of distributed optical fiber temperature sensing system in thermal storage and heating system [1 1340-79]

11340 is Application of distributed optical fiber temperature sensing system in heat network leakage monitoring [1 1340-80]

$113401 \mathrm{~T} \quad$ Research and application of temperature distributed measurement in geothermal well [11340-81]

$113401 \mathrm{U} \quad$ Research progress on coal mine laser methane sensor [1 1340-82]

$113401 \mathrm{~V} \quad$ Application of distributed optical fiber temperature sensing system in oil storage tank fire monitoring [1 1340-83]

11340 1W Research on VCSEL interference analysis and elimination method [1 1340-84]

$113401 \mathrm{~N} \quad$ Numerical assessment of temperature uncertainty of Raman-based distributed temperature sensor with loop configuration [1 1340-85]

$113401 \mathrm{Y} \quad$ Optical fiber sensors for coal mine shaft integrity and equipment condition monitoring [1 1340-86]

$1134012 \quad$ Application of fiber optic sensors for vibration and ignition monitoring of a belt conveyor system [1 1340-88]

1134020 Study of quasi-distributed optical fiber methane sensors based on laser absorption spectrometry [1 1340-90] 


\section{Authors}

Numbers in the index correspond to the last two digits of the seven-digit citation identifier (CID) article numbering system used in Proceedings of SPIE. The first five digits reflect the volume number. Base 36 numbering is employed for the last two digits and indicates the order of articles within the volume. Numbers start with 00, 01, 02, 03, 04, 05, 06, 07, 08, 09, OA, OB...0Z, followed by 10-12, 20-2Z, etc.

An, Yan, 06

Bian, Jiaming, 08

Bu, Manman, $1 G$

Chang, Jun, 20

Chen, Baodan, $\mathrm{OQ}$

Chen, Jizhong, $\mathrm{OA}$

Chen, Qianlong, 04

Chen, Weijuan, $1 \mathrm{~L}$

Chen, Xin, 1A, 1N

Chen, Yajie, $1 \mathrm{~L}$

Chen, Zhihao, $1 \mathrm{~L}$

Cheng, Min-hui, oJ

Cheng, Peng, OW

Deng, Chi, IP

Di, Fagui, OX, 1D

Ding, Kuo, OC

Ding, Yaqian, 18

Dong, Jun, OJ

Dong, Keyan, 06

Dong, Yuanyuan, IW

Du, Chenlin, 11

DU, Rui, 1R, 1S, 1T, 1V, 1X

En, Yunfei, ON

Fan, Jin-ying, OP

Fan, Shoutao, OR

Fan, Yupei, OQ

Feng, Yafei, 02

Fu, Chaoshuai, 1R, 1T, 1V

Fu, Jianwei, $1 Y$

Fu, Yang, 07

Gao, Kan, 18

Gao, Liang, 06

Ge, Huiliang, Ol

Geng, Zhaoxin, $1 \mathrm{~J}$

Gong, Weihua, 20

Gong, Xiaoyu, OC

Grattan, Kenneth T. V., 1M, 1Q, 1U, 1W, 1Y, 1Z, 20

Guan, Hua, 02

Guo, Mengyuan, OK

Han, Dong-dong, $0 \mathrm{~J}$

Hao, Yang, $1 \mathrm{~N}$

$\mathrm{He}$, Shijun, $\mathrm{OQ}$

Hou, Moyu, 12

$\mathrm{Hu}, \mathrm{Bin}, \mathrm{O2}$

$H U$, Binxin, $1 Y$

Hu, Jie, $1 M$

$\mathrm{Hu}$, Jun-hui, OP

Hu, Zheng, $O Q$

Huang, Ruqing, 11
Huang, Yun, ON

Hui, Fei, 09, 00

Ji, Wei, 18

Ji, Yuefeng, 17, 19, 1E, 1F, 1G, 1H

Jia, Guanghui, 1Q

Jia, Lidong, 1V

Jia, Shuhai, 08, 0A

Jia, Wu, $1 \mathrm{H}$

Jiang, Daming, 1Q, $1 U$

Jiang, Qi, OE

Jin, Guang Xian, 1M, 1Q, 1U, 1W

Jin, Junjie, $O B$

Jin, Mengqun, $\mathrm{Ol}$

Jing, Zhaoman, OF, OG

$\mathrm{Ke}$, Xizheng, $\mathrm{O3}$

Kong, Lingyu, IW

Kong, Qingshan, 13

Lai, Canxiong, ON

Lei, Sichen, 03

Lei, Ting, OT

Li, Dexin, OB

Li, Fang, 13, 14

$\mathrm{Li}$, Haiyang, 02

Li, Hui, 1E, 1F, 1G, 1H

Li, Jingcong, $1 \mathrm{~J}$

$\mathrm{LI}$, Jinze, $0 \mathrm{Z}$

Li, Junyi, 1P, 1S

Li, Maochun, 09, 00

$\mathrm{Li}, \mathrm{Na}, 1 \mathrm{R}, 1 \mathrm{~S}, 1 \mathrm{~T}, 1 \mathrm{~V}, 1 \mathrm{X}$

Li, Runchun, $1 \mathrm{Z}$

Li, Shuwang, ON

Li, Xiangyun, 02

Li, Yanfang, 1U, 20

Li, Yiyuan, OK

Li, Yuanzhen, $1 Y$

Liang, Dezhi, 11

Liang, Hong-guang, OY

Liang, $\mathrm{Hu}, 1 \mathrm{C}$

Liang, Xiao, $1 \mathrm{~J}$

Liu, Bo-han, 05, 0D, OH, 1A, 1B, 1C, 1N

Liu, Chen, $O B$

Liu, Jian, $1 \mathrm{~F}$

Liu, Jianben, 08

Liu, Jiancai, $1 \mathrm{C}$

Liu, Ji-hong, OJ, OV

Liu, Tong Yu, 1M, 1Q, 1U, 1W, 1Y, 1Z, 20

Liu, Xiangnan, $1 Y$

Liu, Xuran, OF, OG

Liu, Zhen, 17 
Liu, Zhenya, $1 \mathrm{U}$

Liv, Zhiming, $1 \mathrm{~J}$

LU, Guoguang, ON

Luo, Hui, 1P

Luo, Shihui, $1 \mathrm{P}$

Ma, Gang, $1 Y$

Ma, Lilong, 13, 14

Ma, Lin, $1 \mathrm{~N}$

Ma, Longxin, 11

Ma, Si-ye, 04, OU

Marcal, A. R. L., OX, 1D

Mei, Ying, 10

Meng, Hui, 1M, 1Q, 1U, 1W

Min, Fu, OS

Mo, Jia-qing, OL

Nan, Youxin, 03

$\mathrm{Ni}$, Dong, $1 \mathrm{E}$

$\mathrm{Ni}$, Minye, $1 \mathrm{G}$

Niu, Hang, OX, 1D

Pan, Liang, 1T, $1 \mathrm{X}$

Peng, Jun, 08, 0A

Qian, Fengchen, 15

Qiao, Yuanzhe, OR

Qin, Wei, OE

Qin, Zi-xiong, OP

Qiu, Huacheng, OS

Qiu, Jia-xin, OU, 18

Ran, Zengling, OS

Ren, Junjiang, 04, 18

Ren, Kai-li, 0J

Rong, Liang, 04, 18

Rong, Ling, OM

Rong, Xiaoxu, 12

Ruan, Shuangchen, 11

Shao, Yan, $1 \mathrm{H}$

Shi, Meiling, $1 \mathrm{~K}$

Shi, Zhidong, 1Q, $1 \mathrm{U}$

Soga, Kenichi, 10

Su, KUo, OB

Su, Xueqiong, OW

Su, Yudan, $1 \mathrm{H}$

Sun, Jinglei, $1 \mathrm{H}$

Sun, Tong, 1M, 1Q, 1U, 1W, $1 \mathrm{Z}$

Tang, Cai-jie, OY

Tang, Ruoxiang, 1B

Tian, Chang, 1P, 1S

Wan, Xun, OC

Wang, Ding, OB

Wang, Fuzhai, $O Q$

Wang, Gonghua, $1 Y$

Wang, Guangquan, $1 \mathrm{H}$

Wang, Huaipeng, $1 \mathrm{~K}$

Wang, Jin, OW

Wang, Jingyu, $1 \mathrm{~W}$

Wang, Jiqiang, 12

Wang, Jiuwang, 07

Wang, Li, OW

Wang, Lianping, 04

Wang, LiJuan, OM
Wang, Liqiu, Ol

Wang, Ming-chao, OY

Wang, Xiang, 12

Wang, Xue-feng, OY, 16

Wang, Yachun, 10

Wang, Ying, 1L

Wang, Yongchao, OV

Wang, Yubao, OF, OG, OK

Wang, Yue-ze, 05, OD, OH, 1B

Wang, Yun, 07

Wang, Ze-yu, 04, OU

Wang, Zhaowei, 20

Wang, Zhenpeng, 12

Wang, Zhuo, 12

Wangwang, Wang, $1 Q$

Wei, Dong, 07

Wei, Hua, 02

Wei, Wen-jie, ou

Wei, Yu Bin, 1M, 1U, 20

Wu, Cong, OT

Wu, Xiao-le, 05, OD, OH, 1B

Xiao, Chun, OU

Xiao, Fei, 15

Xiao, Yuming, 19

Xie, Liangping, $0 \mathrm{C}$

Xie, Yan, 06

Xie, Zhendong, os

Xin, Chaojun, $1 \mathrm{~K}$

Xiong, Tingting, 04

Xiong, Yiwei, $\mathrm{OZ}$

$\mathrm{XU}$, Shouping, OA

$\mathrm{Xu}$, Tuanwei, 13, 14

$X U$, Xiaomin, 10

$\mathrm{Xu}$, Yiyun, 06

$\mathrm{XU}, \mathrm{Zhihao}, \mathrm{OZ}$

Yan, Huanhuan, OW

Yang, Chen, $1 \mathrm{~K}$

Yang, Chengwu, 18

Yang, Kaiheng, 13, 14

Yang, Li, OJ

Yang, Xiaojun, 1R, 1S, 1T, 1V, 1X

Yang, Xiuyu, 12

Yang, Yanguang, OS

Yang, Yufeng, 03

Yao, Hong, $1 \mathrm{~K}$

Ye, Yalin, 15

You, Jinchuan, 12

Yu, Dafei, OB

Yu, Fa-shuo, OL

$\mathrm{Yu}$, Hongyu, OD, $\mathrm{OH}$

YU, Yongqin, 11

Yuan, Xiaocong, OT

Zhan, Tianshun, $1 \mathrm{~F}$

Zhang, Chunxi, OC

Zhang, Dongsheng, 1P

Zhang, Dongxu, 11

Zhang, Dongyu, 19

Zhang, Haiyan, 16 
Zhang, Hang, $1 M, 1 Q, 1 U$

Zhang, Huimin, $1 Y$

Zhang, Huisong, OW

Zhang, Jia, OV

Zhang, Jiawei, 17, 19

Zhang, Jie, $1 \mathrm{E}$

Zhang, Shixi, 1 Z

Zhang, Shuo, 08

Zhang, Shuyin, 1A

Zhang, Tingting, 20

Zhang, Wen-yu, OU

Zhang, Xiaodong, OX, OZ, 10, 1D

Zhang, Yufeng, 11

Zhao, Chen, 16

Zhao, Ran, 07

Zhao, Zhen, $\mathrm{OZ}$

Zhen, $\mathrm{Xi}, 11$

Zheng, Huan, 02

Zheng, Xiang-xiang, $\mathrm{OL}$

Zheng, Xiaoyu, OV

Zhong, Qi, OR

Zhou, Jian-ming, OP

Zhou, Xing, OA

Zhou, You, 07

Zhu, Feng, $1 Y$

Zhu, Ling, 09

Zhu, Liu-qian, $0 \mathrm{~J}$

Zhu, Xiaofei, 1R, 1S, 1T, 1V, 1X

Zhuang, Yan, 15

Zuo, Wen-long, 05, 1A, $1 \mathrm{C}$

Proc. of SPIE Vol. $113401134001-9$

Downloaded From: https://www.spiedigitallibrary.org/conference-proceedings-of-spie on 26 Apr 2023 Terms of Use: https://www.spiedigitallibrary.org/terms-of-use 
Proc. of SPIE Vol. 11340 1134001-10

Downloaded From: https://www.spiedigitallibrary.org/conference-proceedings-of-spie on 26 Apr 2023 Terms of Use: https://www.spiedigitallibrary.org/terms-of-use 


\title{
Conference Committees
}

\author{
Conference Chairs
}

Guangjun Zhang, Southeast University (China)

Byoungho Lee, Seoul National University (Korea, Republic of)

John Greivenkamp, The University of Arizona (United States)

Conference Review Committee

Desheng Jiang, Wuhan University of Technology (China)

Dianyuan Fan, Shenzhen University (China)

Huilin Jiang, Changchun University of Science and Technology (China)

Junhao Chu, Shanghai Institute of Technical Physics, Chinese Academy of Sciences (China)

Jianyu Wang, Chinese Academy of Sciences, Shanghai Branch (China)

Jianquan Yao, Tianjin University (China)

Jiancheng Fang, Beihang University (China)

Jiubin Tan, Harbin Institute of Technology (China)

Lin Li, University of Manchester (United Kingdom)

Lijun Wang, Changchun Institute of Optics, Fine Mechanics and Physics, Chinese Academy of Sciences (China)

Min Gu, University of Shanghai for Science and Technology (China)

Qionghai Dai, Tsinghua University (China)

Shibin Jiang, AdValue Photonics, Inc. (United States)

Shenggang Liu, University of Electronic Science and Technology of China (China)

Shouhuan Zhou, North China Research Institute of Electro-Optics (China)

Toyohiko Yatagai, Utsunomiya University (Japan)

Wenqing Liu, Anhui Institute of Optics and Fine Mechanics, Chinese Academy of Sciences (China)

Wei Wang, Beijing Institute of Aerospace Control Device of CASC (China)

Yueguang Lv, Chinese Academy of Engineering (China)

Zuyan Xu, The Technical Institute of Physics and Chemistry of the Chinese Academy of Sciences (China)

Conference Program Committee

Chaoyang Lu, University of Science and Technology of China (China)

Daoxin Dai, Zhejiang University (China)

Dong Liu, Zhejiang University (China)

Haimei Gong, Shanghai Institute of Technical Physics, Chinese Academy of Sciences (China)

Hongbo Sun, Tsinghua University (China)

Jin Lu, Tianjin Jinhang Institute of Technical Physics (China)

Jinxue Wang, SPIE 
Jin Yu, Shanghai Jiao Tong University (China)

Jian Zhang, Shanghai Institute of Ceramics, Chinese Academy of Sciences (China)

Min Gu, University of Shanghai for Science and Technology (China)

Min Qiu, Westlake University (China)

Michelle Sander, Boston University (United States)

Mengxia Xie, Beijing Normal University (China)

Pu Zhou, National University of Defense Technology (China)

Sven Hofling, Universität Wurzburg (Germany)

Shibin Jiang, AdValue Photonics, Inc. (United States)

Suijian Xue, National Astronomical Observatories, Chinese Academy of Sciences (China)

Takunori Taira, RIKEN SPring-8 Center (Japan)

Vincenzo Palleschi, Institute of Chemistry of Organic Metallic Compounds (Italy)

Wenxue Li, East China Normal University (China)

Xiaocong Yuan, Shenzhen University (China)

Xuejun Zhang, Changchun Institute of Optics, Fine Mechanics and

Physics, Chinese Academy of Sciences (China)

Yadong Jiang, University of Electronic Science and Technology of China (China)

Yongtian Wang, Beijing Institute of Technology (China)

Yuegang Fu, Changchun University of Science and Technology (China)

Zhiping Zhou, Peking University (China)

Zhe Wang, Tsinghua University (China)

Ziyang Zhang, Westlake University (China)

\section{Session Chairs}

1 Optical Fiber Sensors and Communication

Deming Liu, Huazhong University of Science and Technology (China)

Yuefeng Ji, Beijing University of Posts and Telecommunications (China)

Xiongyan Tang, China Unicom Corporation (China)

Zhiguo Zhang, Beijing University of Posts and Telecommunications (China)

Weihong Bi, Yanshan University (China) 


\section{Introduction}

AOPC 2019, the Annual Conference of Chinese Society of Optical Engineering (CSOE), was one of the largest academic and industrialization activities in the field of optical and optoelectronic technology in China. The Organizing Committee intended to build a potential platform together with academic exchanges, industry exhibitions, and cooperation negotiations in one. There were 11 technical conferences and 38 conference sessions, and we sincerely hope that the research and development of optoelectronic technology were promoted, and that international cooperation in industry and in the optical and optoelectronic fields were enhanced.

AOPC 2019 was sponsored by SPIE and the Chinese Society for Optical Engineering; the Optical Society of Korea (OSK), Optics and Photonics Society of Singapore (OPSS), European Optical Society (EOS), Optical Society of Japan (OSJ) were the technical co-sponsors. There were also 48 Cooperative Organizations that supported the conference.

We received over 930 total contributions from more than 15 countries, including United States, United Kingdom, Germany, France, Spain, Australia, Canada, Mexico, Brazil, Japan, the Republic of Korea, Thailand, Singapore, the Russian Federation, China, and so on. There were 554 contributions published in SPIE Proceedings.

After careful discussion, we suggested four keynote speeches which were presented by famous scientists from Germany, Australia, Japan, and China. There were 110 excellent invited talks, 45 of them are from overseas, their inclusion represented a first-class level in the field of optics and photonics technology. On behalf of the Organizing Committee of AOPC, I express the thanks to all the invited speakers and authors for their contributions and supports to the conference.

Finally, on behalf of the Chairmen and the Organizing Committee of AOPC, I would like to heartily thank for our sponsors and Cooperating Organizations for all they have done for the conference, to all of the participants and friends for their interests and efforts in helping us to make the conference success. Also, thanks to the Program Committee for their effective work and valuable advice; especially the AOPC 2019 Secretariat and SPIE for their tireless effort and outstanding services in preparing the conference and publishing the Proceedings.

We are glad that AOPC 2019 had great success! Hope to see you next year!

Guofan Jin 
Proc. of SPIE Vol. 11340 1134001-14

Downloaded From: https://www.spiedigitallibrary.org/conference-proceedings-of-spie on 26 Apr 2023 Terms of Use: https://www.spiedigitallibrary.org/terms-of-use 